\title{
Evaluating Impacts of Financial Risks on Schedule Delays of International Highway Projects in Vietnam using Structural Equation Model
}

\author{
Hong Anh $\mathrm{Vu}^{\mathrm{a}}$, Cao Cuong Vu $\mathrm{u}^{\mathrm{b}}$, Jianqiong Wang ${ }^{\mathrm{a}}$, Lianxing Min ${ }^{\mathrm{c}, *}$ \\ ${ }^{a}$ School of Economics and Management, Southwest Jiaotong University, Chengdu, 610031, China \\ ${ }^{b}$ Postgraduate Office, Le Quy Don Technical University, Hanoi, 100000, Vietnam \\ ${ }^{c}$ School of Management, Chengdu University of Traditional Chinese Medicine, Chengdu, 611137, China
}

\begin{abstract}
Schedule delay (SD) in International Highway Projects (IHPs) has a higher risk than traditional projects and causes a significant detrimental impact on efficiency, cost, and reputation of project investment. As one of the main reasons causing SD, the financial problem was discussed in the literature but was either usually listed very generally or its impacts on project performance were insufficiently described. This study focuses on the financial-related factors affecting SD in IHPs, and employs a factor analysis technique to identify and categorize them using the 207 questionnaire data from the IHPs in Vietnam. Then, the study applies the Structural Equation Model (SEM) to assess the influences of identified factors on SD as well as interactions among them. The empirical results reveal that the financial-related risk elements of SD could be grouped into five major factors in IHPs. In accordance with the effects on SD, the five factors from highest to lowest respectively are changing economic environment(CEE), policy changes (PC), lack of financial capital (LFC), delayed payment (DP), and poor financial management (PFM). The study also discusses the implications of empirical results to effectively avoid, reduce, or even eliminate the impacts of financial-related risks on SD, and provides a set of countermeasures to help the local government and international contractors to mitigate the SD of IHPs in Vietnam, as well as in developing countries that possess similar conditions to those in Vietnam.
\end{abstract}

Keywords: risk management; schedule delay; international highway projects; structural equation model; Vietnam

(Submitted on November 21, 2017; Revised on December 23, 2017; Accepted on January 24, 2018)

(C) 2018 Totem Publisher, Inc. All rights reserved.

\section{Introduction}

Schedule delay is one of the most common, costly, complex and risky problems encountered in a construction project [3]. Delays occur in almost every construction project and the magnitude of these delays varies considerably from project to project. Many studies have confirmed that highway construction projects have higher risks than other construction projects due to entailing high capital outlays and intricate site conditions [24]. Highway construction projects are spread over a wider geographic area and are threated from various underground conditions [10]. Vietnam is one of many developing countries attempting to develop highway infrastructure construction. However, there are a number of issues leading to SD of highway projects including: starting step is a little bit late, level of technology and management is quite low, and reasons of schedule delays in highway projects are not properly focused. Relating research almost always focused on developed countries, and referencing the significance of those research to developing counties has limitations. Vietnam is a newly-developing country, and its highway infrastructure demand and capacity are truly huge. Vietnam, which did not have any highway before 2002, is a main source of IHPs. From 2008, the Vietnamese government started an ambitious plan relating to developing highway infrastructure. Nevertheless, a lack of technology and capital made Vietnamese highway projects based on international contracts very complicated. As it is mentioned in previous research [11], international construction projects, including highways, always face higher risks of political, economic, institutional and legal environment problems compared to other kinds of project. These factors indeed lead to significant delays of highway projects in Vietnam, resulting in extreme adverse outcomes that bring the owner loss of potential revenue and increase the costs of the contractors in overhead. These factors also are sources of issues relating to delay responsibility, which may result in conflicts leading to costly legal litigation [1,3].

* Corresponding author.

E-mail address:minlx@foxmail.com 
The financial problems, such as fund raising and management, have become the most important problem for Vietnam as well as other developing countries. General international highway projects have more participant parties; therefore, it is more complicated than other general projects. It involves many specific financial factors and aggravates the construction schedule delays. Therefore, it is very necessary to investigate SD, which is caused by financial issues, of international highway projects in Vietnam. Despite the fact that this kind of study cannot absolutely eliminate project delay, it can help all parties attempt effective measures that can reduce or even prevent effects of risks.

Previous research has studied recognition and assessment on risks of highway projects in a number of developed nations, such as the United State, China, Taiwan, and the UAE, but only a few researches have been attempted in Vietnam. Thus, in this study, we systematically analyze delay of project due to financial risks using a questionnaire to survey specific highway projects in Vietnam. The study also utilizes the SEM method to assess the impacts of every single risk factor as well as impacts among risk factors.

\section{Causes of financial-related delays}

$\mathrm{SD}$, which is often encountered in construction projects, is defined as when the owner and the contractor are not able to meet the completed date signed in the contract [2], or the completed date of the project is later than the planned date, which leads to schedule delays of the whole contract [6]. SD of construction projects are especially obvious in developing countries. Researchers have presented a lot of research revealing causes of this problem wherein financial factor was pointed out as the one of the main reasons affecting the construction's progress. Previous research has revealed the financial-related factor, which stems from a variety of reasons, e.g., payment difficulties from agencies; poor contractor management; material procurement; difficulty for loans; and price fluctuations effecting project delays, which is one of the main reasons causing delays of engineering construction progress and cost overrun in Ghana [13]. In Thailand, factors relating to survey and design, potential of the contractor, and capable supervision were reported as the main factors influencing large engineering project delays, of which the lack of resources, such as the contractor's financial difficulties, is the main factor that leads to delays in construction projects [20]. In Malaysia, financial-related factors that lead to delays in Malaysian construction projects were revealed as financial issues of the owner, such as, financial difficulties and economic problems, delayed payments, financial and cash flow problems of the contractors, and external factors of poor economic conditions, i.e., currency and inflation rate [3]. Otherwise, Zayed et al. have presented that financial risk ranks second highest in macro level (company) areas in Chinese highway projects [24].

In different countries and places under different stages, risk factors influencing the construction progress are not the same. Through an analysis from perspectives of different relevant participants, Le Hoai et al. have revealed that a lack of fiscal capacity is one of the seven factors influencing Vietnamese engineering construction progress [15]. Researchers have also figured out that factors causing construction schedule delays in Vietnam include 7 types and 59 specific factors, in which fiscal capacity is one of the main factors [17]. Economic, political and legal risks are other main factors that foreign firms may face within Vietnam [16].

To identify risk factors, many quantitative methods were used. Zayed et al. developed a risk evaluation model of Chinese highway projects using a method of analytic hierarchy process [24]. Wenxi et al. have established a fuzzy neural network model for management risks of expressway projects through improving the BP neural network and fuzzy synthetic evaluation method; the latter can objectively evaluate management risks that help the managers make an accurate decision on managing risks in advance. Therefore, an optimized solution can be adopted [23]. Taylan et al. have generated a new hybrid evaluation method for the fuzzy analytic hierarchy processes and fuzzy comprehensive evaluation methods, and they demonstrated their considerable application potentials with empirical results [19]. In addition, El-Sayegh et al. have used the relative important index (RII) to assess and allocate risk in highway projects in the United Arab Emirates [10].

To sum up, in developing countries, SD is a very common phenomenon. There are many factors causing project delays. However, one of the main factors effecting the construction period is the financial factor. If the project does not have enough money, the project execution efficiency will be directly affected. Previous researches have discussed this issue but there are some shortcomings, which mainly reflects in:

(1) From identification risk factors point of view, researches mainly studied global impact factors. Analysis of financial factors effecting construction delay tended to be scattered and limited on induction analysis.

(2) Characteristics of different kinds of infrastructure construction were ignored. For instance, there are many constraint factors that IHPs always face: risks of political, economic, institutional and legal environment, as well as numerous participant units and the large scale of investment compared to that of a general project. Therefore, these particularly need to be analyzed. 
(3) Previous studies just conceptually introduced risk-based approach, but application of the quantitative method is rare. These limited quantitative studies using factor analysis method can effectively assess independent impact of every single factor but cannot provide detailed information with respect to interactions among risk factors.

To deal with the above shortcomings, the current study mainly focuses on financial factors and utilizing the SEM method to investigate impact paths of risk factors in order to help participants attempt reasonable measures in case of occurring relevant circumstances.

\section{Research Method}

The current study adopts a field survey methodology to discover financial-related factors influencing SD of IHPs. This work includes three steps. Firstly, identification of financial risks effecting SD of IHPs is attempted. This step is completed by summarizing and referencing previous researches [1,10,15,16,17,21,24]. Secondly, based on a summary of identification financial risk in the preceding step, we established a survey questionnaire, delivered it and gathered surveyed data. Finally, data analysis is conducted which is comprised of sub-steps: $(i)$ exploratory factors are analyzed using SPSS20 software; (ii) structure a path-effect model of financial risk factors influencing SD of IHPs and present hypotheses; (iii) SEM are analyzed using AMOS20 software to figure out direction and strength of relations among latent variables. The study attempts an analysis method, which includes two parts [5]: measurement model analysis and test structure relation of latent variables. The study uses the maximum-likelihood method as an estimation method. Indicators of analysis and requirements of a good fitting measurement model are as follow:

(1) The ratio of Chi-square and freedom degrees $\left(\chi^{2} / d f\right)$ should be smaller than 3 ;

(2) p value indicates significant behavior and the root mean square error of approximation (RMSEA) should be smaller than 0.05 ;

(3) Goodness of fit index (GFI), normed fit index (NFI), comparative fit index (CFI), Tucker-Lewis index (TLI), and incremental fit index (IFI) should be bigger than 0.9 .

\section{Research Method}

As we mentioned in section 3, the purpose of the first step is to identify financial risk influencing SD of IHPs through literature review. Because publications related to financial-related risks in highway projects are limited, the current study is extended to other sectors in the construction industry. From literature and interview professionals on highway projects in Vietnam, a total of 26 risks are identified and used in a questionnaire designed to gain expertise from construction experts in the highway construction industry in Vietnam.

To improve the risk identification process, risks are generally categorized into internal and external risks using a Breakdown Structure (BRS) according to the source of risks [4,9,10,21]. This categorization method is also found in previous research presented by Zoysa et al. wherein economic risks included internal and external events [25]. In addition, Linh et al. have presented that economic, political, and legal risks are common risks that foreign-construction-related firms always have to face within Vietnam [16]. Therefore, in our study, to categorize financial risks specifically, internal and external risks are then divided into a variety of financial-related risks as depicted in Figure 1. Of which, internal and external risks will be mentioned specifically below.

\subsection{Financial-Related Internal Risks}

\section{Funding source risks}

Smooth operation of engineering construction must be supported by enough expenses. In case of a construction project in progress that runs out of capital, the plan to complete the construction project is definitely influenced. There are six risks that belong to funding source risks (see also Figure 1). Financial difficulties of the owner and difficulty in getting loans from the owner are two main risks leading to finance problems influencing construction progress. Furthermore, the owner's excessive change in orders may lead to time and cost implications for the contractor in construction progress. In addition, the owner's construction fund is not always ready before the start of the engineering construction, and if the financial ability of the contractor is poor and loan capacity of the contractor is difficult, the construction period and cost would be influenced. Otherwise, the unreasonable allocation funds of the government are one of the primary causes leading to out of funding for the project. 


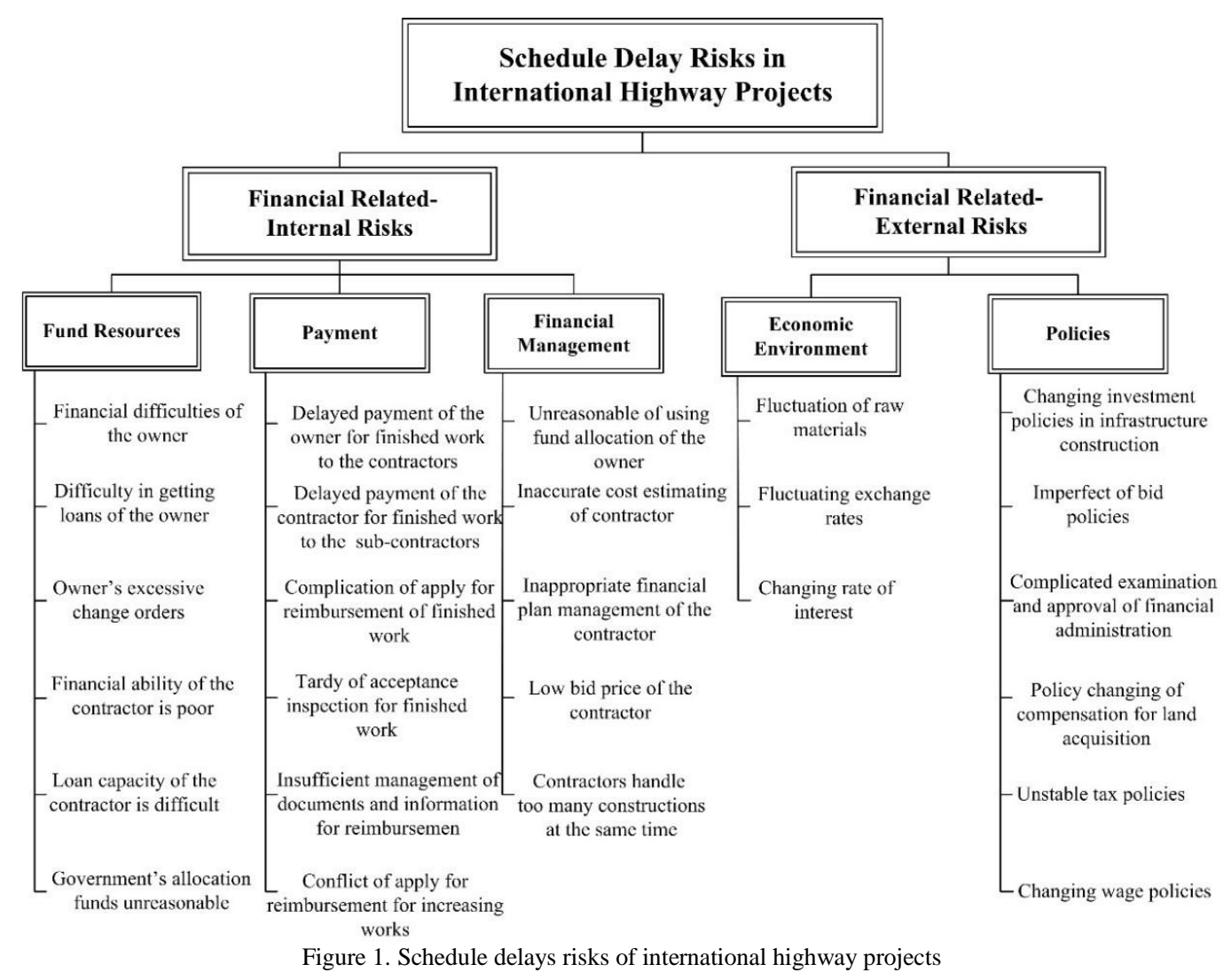

\section{Payment risks}

Finished work that cannot be paid on time leads to a broken capital chain, which effects construction delays. All participants in the project may cause the slow payments, and as long as one party pays slowly, the entire process will be influenced, bringing the project financial difficulties. Delayed payment includes slow paying by the owner for finished work to the contractors, delayed payment by the contractor for finished work done by sub-contractors, complications in applying for reimbursement of finished work, tardy of acceptance inspection for finished work, insufficient management of documents and information for reimbursement, and conflicts in applying for reimbursement of increasing work.

\section{Financial management risks}

Financial management directly influences capital turnover of construction units and even leads to capital chain scission during the construction process, influencing the engineering construction progress. Poor financial management includes: unreasonable use of fund allocation by the owner, inaccurate cost estimation by the contractor, inappropriate financial plan management by the contractor, low bid price by the contractor, and handling too many construction projects at the same time by contractors.

\subsection{Financial-Related External Risks}

\section{Economic environment risks}

The changes in financial markets lead to fluctuations of raw materials, impacting the sources of IHPs and resulting in risks due to price increases during the construction phase. This influences the plan of resource supplier resulting in SD. Furthermore, fluctuating exchange rates and changing rates of interest also influence the profitability of the project.

\section{Policy risks}

The construction process of international projects must strictly obey national and local government laws and policy requirements. Policy changes such as changes in rules and regulations depend on the political situation of the country where the project is taking place. Policy changes include changing investment policies in infrastructure construction, imperfect bid policies, complicated examination and approval of financial administration, policy change of compensation for land acquisition, unstable tax policies, and changing wage policies. 


\section{Questionnaire survey design}

To identify risks impacting SD of IHPs in Vietnam, the current study uses the survey method. The design of the questionnaire will be discussed below in detailed.

In our work, the design of the questionnaire survey plays a crucial role in the results of the study. Firstly, an initial questionnaire was developed that adapted and integrated existing measurements through previous researches, as mentioned in section 3. In order to meet conditions of Vietnamese highway construction projects, a pilot questionnaire was prepared. Secondly, five Vietnamese experts, who have over 20 years of experience in engineering construction, were invited to ask for their expertise on the pilot test. Then, they were also invited to critically review the design and structure of the questionnaire. Their comments and suggestions were used to revise the survey questionnaire. Lastly, the final questionnaire included 26 risks (independent variables) and 3 risk effects (dependent variables) that were identified.

The final questionnaire consists of two parts: the first part focuses on a statistical description and solicitation of general information about respondents, and the second part intends to get the perception on rating each risk and risk effect. Then, the questionnaires are sent through electronic mail, direct delivery (face-to-face), or personal interview. The interviewees were asked to assess impacts of the factors according to a five-number ordinal scale corresponding to different magnitudes from low to high: 1 refers to very low impact, whereas 5 corresponds to very high impact. To collect data, we surveyed recently finished highway projects to avoid any issues of respondents being unable to remember the relevant detailed problems of the projects.

In 2015, 500 distributed questionnaires were delivered to respondents involved in expressway projects in Hanoi (the capital of Vietnam) and its adjacent provinces. We then obtained 261 feedback, of which 207 full responses met criteria, which is established if proportion of sample size and observed variables are at least more than 1:5 [7]. Therefore, those 207 responses were used in the analysis. Summary profile of the respondents is shown in Table 1.

Table 1. Constitutions of the respondents

\begin{tabular}{|c|c|c|c|}
\hline \multirow{2}{*}{ Category } & Sample distribution & Sample size & Percentage (\%) \\
\hline \multirow{4}{*}{ Work experience } & 1-3years & 48 & 23.2 \\
\cline { 2 - 4 } & 4-6years & 61 & 29.5 \\
\cline { 2 - 4 } & 7-10years & 53 & 25.6 \\
\cline { 2 - 4 } & Above 10years & 45 & 21.7 \\
\hline \multirow{4}{*}{ Project participants } & Owner & 47 & 22.7 \\
\cline { 2 - 4 } & Contractor/Subcontractor & 65 & 31.4 \\
\cline { 2 - 4 } & Supervision & 43 & 20.8 \\
\cline { 2 - 4 } & Survey and design & 52 & 25.1 \\
\hline \multirow{3}{*}{ Types of projects } & ODA & 76 & 36.7 \\
\cline { 2 - 4 } & BOT & 27 & 32.9 \\
\cline { 2 - 4 } & BTO & 36 & 13.0 \\
\cline { 2 - 4 } & Others & 17.4 \\
\hline
\end{tabular}

\section{Data analysis}

The data analysis is conducted by two steps: In the first step, the exploratory factors are analyzed by using the SPSS20 software. In the second step, the authors use SEM of the AMOS 20 software to check the selected measurement indexes of the model. Finally, the correlation between variables is verified through the test of the structural model and the regression results.

\subsection{Exploratory Factor Analysis}

\subsubsection{Test Result of Independent Variable}

Factor analysis method was then applied to sort out the main causes of overtime. However, before applying this technique, the suitability of data must be verified. In this regard, our data show that the Kaiser-Meyer-Olkin measure of sampling adequacy was sufficient with a value of 0.876 , and the Barlett's test of sphericity possesses significance at 0.000 , 
indicating that the correlation matrix was not an identity matrix. Both of these parameters revealed that the factor analysis can be applicable. It means that strong correlation among variables was suitable for the factor analysis method.

Principle axis factoring produced a five-factor solution with eigenvalues greater than one (see also Table 2). The promax rotation of principle axis factoring analysis was then used to group factors. Factor grouping based on varimax is displayed in Table 2. The factors and associated variables are noted as follow: changing policies, i.e., CP; delayed payment, i.e., DP; poor financial management, i.e., PFM; changing economic environment, i.e., CEE; and lack of financial capital, i.e., LFC.

Table 2 Results of the factor analysis using promax oblique rotation

\begin{tabular}{|c|c|c|c|c|c|c|}
\hline Cause & Serial number & $\mathrm{CP}$ & DP & CEE & PFM & LFC \\
\hline Policy changing of compensation for land acquisition & CP1 & 0.923 & & & & \\
\hline $\begin{array}{l}\text { Complicated examination and approval of financial } \\
\text { administration }\end{array}$ & $\mathrm{CP} 2$ & 0.836 & & & & \\
\hline Changing investment policies in infrastructure construction & $\mathrm{CP} 3$ & 0.800 & & & & \\
\hline Imperfect of bid policies & $\mathrm{CP} 4$ & 0.785 & & & & \\
\hline $\begin{array}{l}\text { Delayed payment of the owner for finished work to the } \\
\text { contractors }\end{array}$ & DP1 & & 0.896 & & & \\
\hline Complication of apply for reimbursement of finished work & DP2 & & 0.857 & & & \\
\hline Tardy of acceptance inspection for finished work & DP3 & & 0.720 & & & \\
\hline $\begin{array}{l}\text { Delayed payment of the contractor for finished work to the } \\
\text { sub-contractors }\end{array}$ & DP4 & & 0.639 & & & \\
\hline Low bid price of the contractor & PFM1 & & & 0.799 & & \\
\hline Unreasonable of using fund allocation of the owner & PFM2 & & & 0.779 & & \\
\hline Inappropriate financial plan management of the contractor & PFM3 & & & 0.712 & & \\
\hline Fluctuation of raw materials & CEE1 & & & & 0.755 & \\
\hline Fluctuating exchange rates & CEE2 & & & & 0.748 & \\
\hline Changing rate of interest & CEE3 & & & & 0.734 & \\
\hline Financial ability of the contractor is poor & LFC1 & & & & & 0.777 \\
\hline Owner's excessive change orders & LFC2 & & & & & 0.757 \\
\hline Financial difficulties of the owner & LFC3 & & & & & 0.730 \\
\hline Eigenvalues & & 6.711 & 1.91 & 1.58 & 1.29 & 1.216 \\
\hline Variance explained $\%$ & & 39.48 & 11.21 & 9.317 & 7.58 & 7.150 \\
\hline Cumulative Variance explained \% & & 39.48 & 50.69 & 60.01 & 67.59 & 74.74 \\
\hline
\end{tabular}

\subsubsection{Test Result of Dependent Variable}

The test method mentioned in previous sub-section was also used to test dependent variables. The Kaiser-Meyer-Olkin measure achieves a value of 0.699 and Barlett's test of sphericity has significance at 0.000 . This means that the strong correlation among variables was suitable for the factor analysis as well. Eventually, time delay, cost overrun and loss of credibility extract a factor of SD. The factor grouping based on varimax is displayed in Table 3.

\begin{tabular}{|c|c|c|c|c|c|c|}
\hline Factors & Factor labels & Eigenvalue & $\begin{array}{c}\text { Variance } \\
\text { explained } \%\end{array}$ & Consequence & $\begin{array}{c}\text { Factor } \\
\text { loading }\end{array}$ & $\begin{array}{c}\text { Serial } \\
\text { number }\end{array}$ \\
\hline \multirow{2}{*}{1} & $\begin{array}{c}\text { Construction } \\
\text { Schedule Delay }\end{array}$ & 2.300 & 76.68 & Time delay & 0.925 & CSD1 \\
\cline { 4 - 8 } & & & & Cost overrun & 0.781 & CSD2 \\
\cline { 4 - 8 } & & & & Loss of credibility & 0.718 & CSD3 \\
\hline
\end{tabular}

\subsection{Conceptual Model and Research Hypothesis}

According to the exploratory factor analysis above, we then proposed hypotheses as shown in Table 4. 
Table 4. First hypothesis model

\begin{tabular}{|c|c|l|}
\hline Constructs & Hypothesis & \multicolumn{1}{|c|}{ Variable relations } \\
\hline LFC & H1 & LFC for direct significant influence on the SD \\
\hline PFM & H2 & PFM for direct significant influence on the SD \\
\hline DP & H3 & DP for direct significant influence on the SD \\
\hline CP & H4 & CP for direct significant influence on the SD \\
\hline CEE & H5 & CEE for direct significant influence on the SD \\
\hline
\end{tabular}

Schedule delay risk is determined jointly by various risk factors. It is necessary to analyze various correlations among the variables and the relevance of risk consequences to explore the risk transmission mechanism. According to Hong et al., good relations among project's participants will help all project participants to use their resources effectively and share benefits and risks of the project, resulting in accomplishing the goal of the project in which all project participants would be satisfied [14]. Therefore, the hypotheses of the interaction relations among related risk factors were proposed in the study as shown in Table 5.

Table 5. Second hypothesis model

\begin{tabular}{|c|c|l|}
\hline Constructs & Hypothesis & \multicolumn{1}{|c|}{ Variable relations } \\
\hline LFC & H1-1 & LFC by affects DP caused the probability of SD \\
\hline PFM & H2-1 & PFM by affects DP caused the probability of SD \\
\hline
\end{tabular}

According to Alien Eyes' Risk model [22], national- and market-level risk of an international project impact projectlevel risk factors in a single direction. Obviously, CP and CEE concern the national- and market-level risks, while LPC, DP, and PFM belong to the category of project-level risk. Therefore, hypotheses of interaction relations among risk factors can be assumed as below (see also Table 6).

Table 6. Third hypothesis model

\begin{tabular}{|c|c|l|}
\hline \multirow{2}{*}{ Constructs } & Hypothesis & \multicolumn{1}{c|}{ Variable relations } \\
\hline \multirow{3}{*}{ CP } & H4-1 & CP due to impact of LFC causing probability of SD \\
\cline { 2 - 3 } & H4-2 & CP due to impact of DP causing probability of SD \\
\cline { 2 - 3 } & H4-3 & CP due to impact of PFM causing probability of SD \\
\hline \multirow{3}{*}{ CEE } & H5-1 & CEE due to impact of LFC causing probability of SD \\
\cline { 2 - 3 } & H5-2 & CEE due to impact of DP causing probability of SD \\
\cline { 2 - 3 } & H5-3 & CEE due to impact of PFM causing probability of SD \\
\hline
\end{tabular}

\subsection{Measurement Model Analysis}

Generally, confirmatory factor analysis is used to test the adequacy of the model. The adequacy test of measurement is based on reliability, convergent validity and discriminant validity test.

As seen in Table 7, obtained values of loading factors of latent variables are bigger than 0.7 ; therefore, surveyed data and adopted model have excellent internal consistency. The Cronbach's alpha values of latent variables are bigger than 0.7 as well; thus, the reliability of the adopted model also reached the requirement of the test.

Convergent validity measurement was verified through two standards presented by Fornell and Larcker: $(i)$ loading values of all indicators should be bigger than 0.7 and p values less than 0.05 , and (ii) average variance extracted (AVE) of latent variables should be bigger than 0.5 [12]. As it is shown in Table 7, loading values and AVE of all indicators satisfied those standards; thus, the convergent validity of the model was satisfied.

As shown in Table 8, AVE square roots among latent variables are higher than the correlation coefficients among latent variables and other latent variables in the model. It simply means that the validity measurement is also distinguished according to the standard proposed by Fornell et al. [12].

Regarding to the verification factors of the measurement model analysis (see also in Figure 2), we obtained the ratio of Chi-square and freedom degrees $\left(\chi^{2} / d f\right)$, as well as the values of P, RMSEA, GFI, NFI, CFI, TLI, and IFI (see also in Table 9 ). These values definitely satisfy requirements of well-fitting measurement model as mentioned in section 3 . 
Table 7. Latent variable, composite reliability, total variance, Cronbach's alpha and AVE

\begin{tabular}{|c|c|c|c|c|c|}
\hline Constructs & Item & $\mathrm{p}$ & Indicator load & Cronbach's alpha & AVE \\
\hline \multirow{4}{*}{$\mathrm{CP}$} & CP1 & $* * *$ & 0.877 & \multirow{4}{*}{0.907} & \multirow{4}{*}{0.712} \\
\hline & CP2 & $* * *$ & 0.862 & & \\
\hline & CP3 & $* * *$ & 0.827 & & \\
\hline & CP4 & $* * *$ & 0.807 & & \\
\hline \multirow{4}{*}{ DP } & DP1 & $* * *$ & 0.827 & \multirow{4}{*}{0.881} & \multirow{4}{*}{0.653} \\
\hline & DP2 & $* * *$ & 0.831 & & \\
\hline & DP3 & $* * *$ & 0.785 & & \\
\hline & DP4 & $* * *$ & 0.788 & & \\
\hline \multirow{3}{*}{ CEE } & CEE1 & $* * *$ & 0.777 & \multirow{3}{*}{0.804} & \multirow{3}{*}{0.582} \\
\hline & CEE2 & $* * *$ & 0.711 & & \\
\hline & CEE3 & *** & 0.798 & & \\
\hline \multirow{3}{*}{ PFM } & PFM1 & $* * *$ & 0.802 & \multirow{3}{*}{0.809} & \multirow{3}{*}{0.586} \\
\hline & PFM2 & $* * *$ & 0.762 & & \\
\hline & PFM3 & $* * *$ & 0.731 & & \\
\hline \multirow{3}{*}{ LFC } & LFC1 & $* * *$ & 0.753 & \multirow{3}{*}{0.798} & \multirow{3}{*}{0.568} \\
\hline & LFC2 & **** & 0.722 & & \\
\hline & LFC3 & $* * *$ & 0.785 & & \\
\hline \multirow{3}{*}{ SD } & CSD1 & **** & 0.919 & \multirow{3}{*}{0.846} & \multirow{3}{*}{0.661} \\
\hline & CSD2 & $* * *$ & 0.732 & & \\
\hline & CSD3 & $* * *$ & 0.776 & & \\
\hline
\end{tabular}

Note: $* * *$ indicates $p<0.001$

Table 8. Square of AVE and correlation coefficients between latent variables

\begin{tabular}{|c|c|c|c|c|c|c|}
\hline & SD & LFC & CEE & PFM & DP & CP \\
\hline SD & 0.661 & & & & & \\
\hline LFC & 0.430 & 0.568 & & & & \\
\hline CEE & 0.402 & 0.180 & 0.582 & & & \\
\hline PFM & 0.415 & 0.166 & 0.263 & 0.586 & & 0.653 \\
\hline DP & 0.552 & 0.342 & 0.316 & 0.310 & 0.239 & 0.712 \\
\hline CP & 0.316 & 0.158 & 0.182 & 0.187 & 0.9 \\
\hline
\end{tabular}

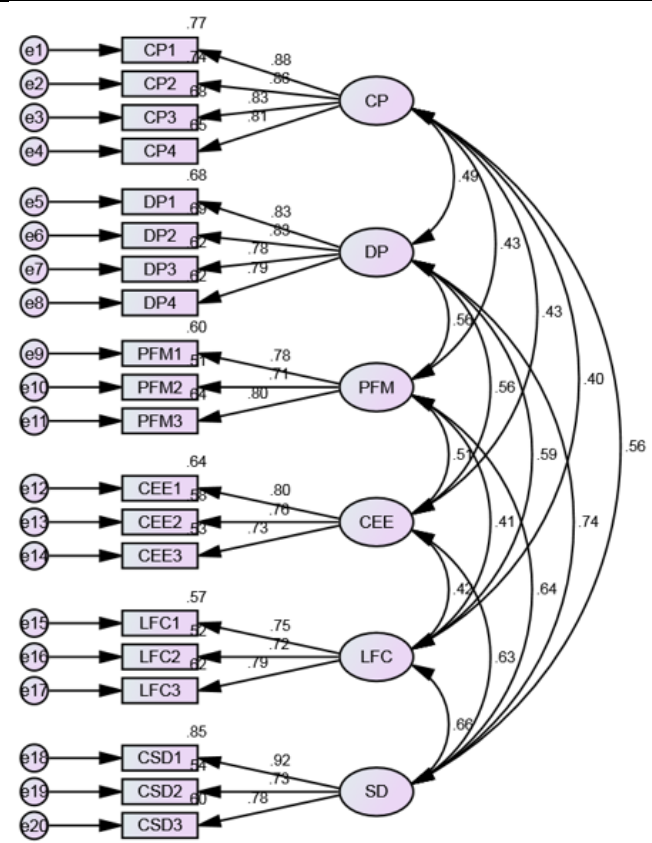

Figure 2. Measurement model indicating impact of financial-related risks on SD of IHPs

\subsection{Structural Model Analysis}

In the study, we used the maximum likelihood method to estimate model parameters. The test of fit model, i.e., structural model analysis (see also in Figure 3), is accepted if all parameters meet the requirements as mentioned in section 3. As seen in Table 10, values of Chi-square and freedom degrees $\left(\chi^{2} / d f\right)$, values of P, RMSEA, GFI, NFI, CFI, TLI, and IFI definitely satisfy those requirements. 
Table 9. Measurement model fitting summary

\begin{tabular}{|l|c|c|c|c|c|c|c|c|}
\hline \multicolumn{1}{|c|}{ Model } & $\chi^{2} / d f$ & $\mathrm{P}$ & RMSEA & GFI & NFI & CFI & TLI & IFI \\
\hline Default & 1.367 & 0.002 & 0.042 & 0.908 & 0.915 & 0.975 & 0.970 & 0.976 \\
\hline Saturation & & & & 1.000 & 1.000 & 1.000 & & 1.000 \\
\hline Independence & 13.098 & 0.000 & 0.242 & 0.251 & 0.000 & 0.000 & 0.000 & 0.000 \\
\hline
\end{tabular}

\begin{tabular}{|l|c|c|c|c|c|c|c|c|}
\hline \multicolumn{1}{|c|}{ Model } & $\chi^{2} / d f$ & $\mathrm{P}$ & RMSEA & GFI & NFI & CFI & TLI & IFI \\
\hline Default & 1.270 & 0.000 & 0.033 & 0.900 & 0.910 & 0.979 & 0.976 & 0.979 \\
\hline Saturation & & & & 1.000 & 1.000 & 1.000 & & 1.000 \\
\hline Independence & 12.237 & 0.000 & 0.214 & 0.308 & 0.000 & 0.000 & 0.000 & 0.000 \\
\hline
\end{tabular}

\subsection{Hypothesis Test and Effects of Path Analysis}

Through analyzing the structure model, the current study obtained standardized-estimated values of all relation coefficients among latent variables in the model (see also in Table 11).

In this section, significance level ( $\mathrm{p}$ value) and critical ratio (CR) are used to reflect the accuracy of selected data as well as the feasibility of the hypotheses. The selected data or the hypotheses are accepted if $\mathrm{p}$ values are less than 0.5 and CRs are bigger than 1.96, and vice versa. As seen in Table 11, LFC has a significant impact on the construction progress ( $\mathrm{p}$ value is 0.000 , less than 0.5 , and $\mathrm{CR}$ value is 3.357, higher than 1.96); thus, $\mathrm{H} 1$ is accepted. Similarly, p values and $\mathrm{CR}$ values of $\mathrm{H} 2$, H3, H4, H5, H1-1, H2-1, H4-1, H4-2, H4-3, H5-1, H5-2 and H5-3 sequentially are less than 0.5 and higher than 1.96, respectively. Therefore, these hypotheses are also accepted.

Table 11. Regression results

\begin{tabular}{|c|c|c|c|c|c|c|}
\hline Hypothesis & Relations & Coefficient & $\begin{array}{c}\text { Standardized } \\
\text { estimation }\end{array}$ & C.R & p & Range \\
\hline H1 & LFC $\rightarrow \mathrm{SD}$ & $\beta_{16}$ & 0.268 & 3.357 & $* * *$ & Accepted \\
\hline $\mathrm{H} 2$ & $\mathrm{PFM} \rightarrow \mathrm{SD}$ & $\beta_{36}$ & 0.235 & 3.090 & 0.002 & Accepted \\
\hline $\mathrm{H} 3$ & $\mathrm{DP} \rightarrow \mathrm{SD}$ & $\beta_{26}$ & 0.309 & 3.656 & $* * *$ & Accepted \\
\hline $\mathrm{H} 4$ & $\mathrm{CP} \rightarrow \mathrm{SD}$ & $\beta_{46}$ & 0.151 & 2.261 & 0.024 & Accepted \\
\hline $\mathrm{H} 5$ & $\mathrm{CEE} \rightarrow \mathrm{SD}$ & $\beta_{56}$ & 0.197 & 2.555 & 0.011 & Accepted \\
\hline $\mathrm{H} 1-1$ & $\mathrm{LFC} \rightarrow \mathrm{DP}$ & $\beta_{12}$ & 0.337 & 4.000 & $* * *$ & Accepted \\
\hline $\mathrm{H} 2-1$ & $\mathrm{PFM} \rightarrow \mathrm{DP}$ & $\beta_{32}$ & 0.252 & 2.909 & 0.004 & Accepted \\
\hline $\mathrm{H} 4-1$ & $\mathrm{CP} \rightarrow \mathrm{LFC}$ & $\beta_{41}$ & 0.333 & 3.773 & $* * *$ & Accepted \\
\hline $\mathrm{H} 4-2$ & $\mathrm{CP} \rightarrow \mathrm{DP}$ & $\beta_{42}$ & 0.167 & 2.156 & 0.031 & Accepted \\
\hline $\mathrm{H} 4-3$ & $\mathrm{CP} \rightarrow \mathrm{PFM}$ & $\beta_{43}$ & 0.308 & 3.682 & $* * *$ & Accepted \\
\hline $\mathrm{H} 5-1$ & $\mathrm{CEE} \rightarrow \mathrm{LFC}$ & $\beta_{51}$ & 0.321 & 3.461 & $* * *$ & Accepted \\
\hline $\mathrm{H} 5-2$ & $\mathrm{CEE} \rightarrow \mathrm{DP}$ & $\beta_{52}$ & 0.247 & 2.828 & 0.005 & Accepted \\
\hline $\mathrm{H} 5-3$ & $\mathrm{CEE} \rightarrow \mathrm{PFM}$ & $\beta_{53}$ & 0.424 & 4.649 & $* * *$ & Accepted \\
\hline Note $* * *$ indicates $p<0.001$ & & &
\end{tabular}

To indicate relations among latent variables, we demonstrated standardized path coefficients of the structure model as depicted in Figure 3. As we can see in Figure 3, in the case of LFC, PFM, DP, CP, and CEE impact on SD simultaneously, we obtained results that show that there are many effects (in different ways) among latent variables influencing the SD risk model. There are some factors that impact SD directly, while some factors influence SD indirectly. Comprehensive effect is the sum of these two effects [8]. Direct effects of latent variables on SD are sorted from highest to lowest respectively as DP (0.309); LFC (0.268); PFM (0.235); CEE (0.197), and CP (0.151). While the comprehensive influences of latent variables on SD are ordered from highest to lowest as CEE (0.525); CP (0.422); LFC (0.371); DP (0.309); and PFM (0.313), respectively. 


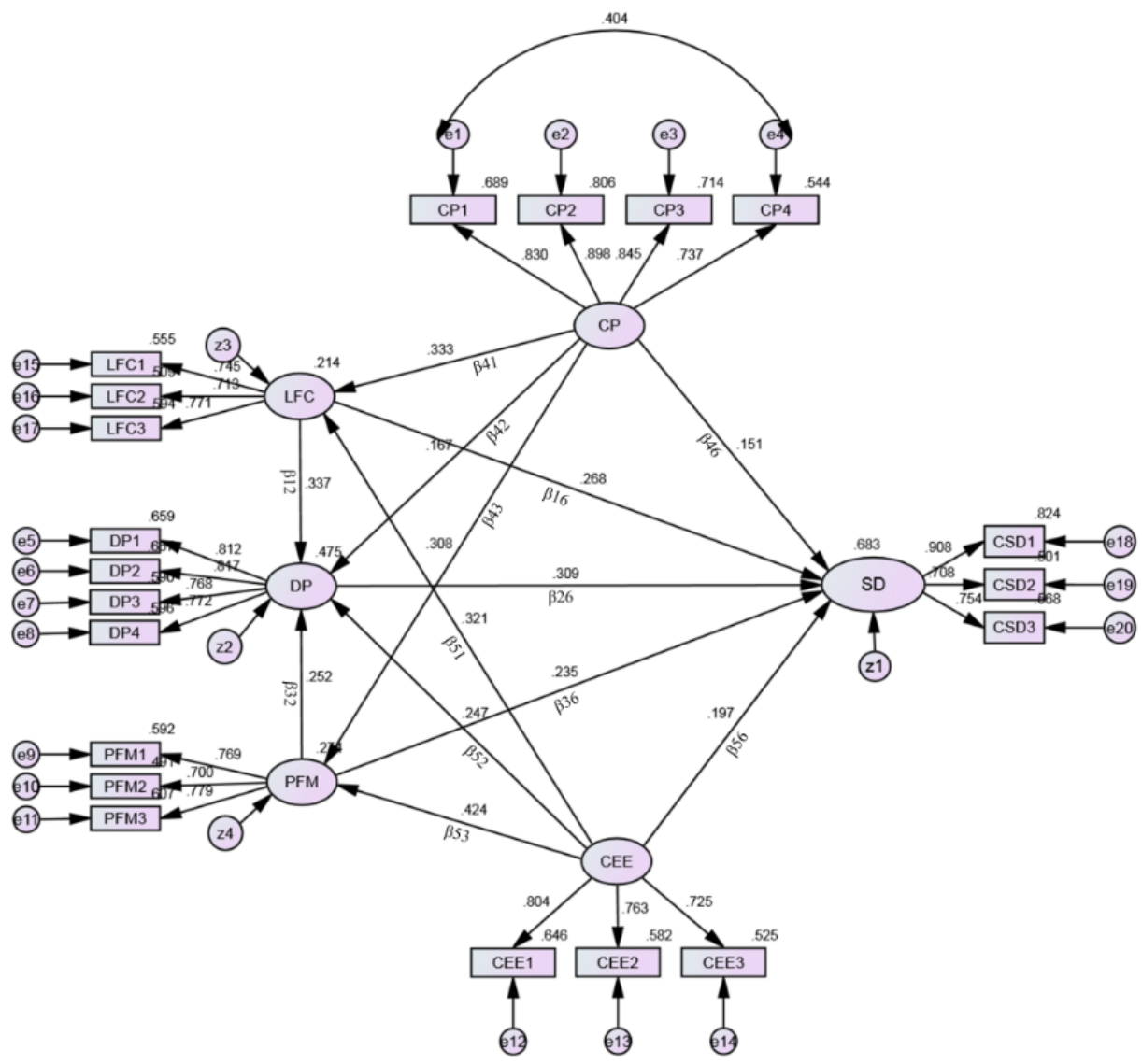

Figure 3. Structural model indicating impact's paths of financial-related risks influence on SD of IHPs

\section{Discussion of SEM Results and Implications}

In this section, we discuss influences of financial-related latent variables on SD based on obtained results in sub-section 6.5 (see also Table. 11 and Figure 3).

\subsection{Impact of CEE}

Regarding impact of CEE, its comprehensive effect is highest (0.525), while its direct effect ranks second. Effect of CEE, apart from directly influencing SD, can indirectly influence SD through directly impacting LFC, PFM, and DP. CEE comprises of fluctuating prices of raw materials, exchange rates, and interest rate changes. Previous researches have presented the cost of raw materials increases proportionally to the fluctuation of foreign exchange rates and interest rates; therefore, it would significantly impact project's cash flow, resulting in timely performance of the project, especially in developing countries, e.g., Ghana, Malaysia [1,3,13]. Concerning raw materials purchase, the price paid by the contractor would be much higher than the original contract price, leading to cost pressures to the contractors, affecting the construction project time limit. In the case of financial market instability and fluctuating ranges of foreign exchange rates and interest rates, the currency risk may influence the fiscal source of the project.

Countermeasures: The project's participants are suggested to pay attention to macroeconomic policy, fiscal policy, and financial-currency policy of the country in order to effectively estimate price fluctuation of materials as well as the influence of exchange rate change. The construction contract should contain price adjustment terms and legal terms to avoid economic risks. Otherwise, the stakeholder is suggested to speed up the process of releasing the loan with reducing loan interest magnitude in order to reduce construction cost.

\subsection{Impact of $C P$}

Concerning impact of $\mathrm{CP}$ on SD, its comprehensive effect ranks second (0.423) while its direct affect is the least $(0.152)$. Apart from directly influencing SD, CP also indirectly influences SD through directly influencing LFC, PFM, and DP. CP consists of complicated examination and approval of financial administration, changing investment policies in infrastructure 
construction, and policy changing of compensation for land acquisition. In a similar investigation's results given by Zayed et al., from the macro-risk aspect, political change possesses the biggest influence on China's highway projects [24]. Ling et al. pointed out that distinctive features of managing projects in Vietnam are really complicated [16]. In addition, procedures for getting approvals and permits often cause payment processes that take a long time, which directly influences project's cash flow. Moreover, due to the high demand of infrastructure projects in Vietnam, changes in government leaders may lead to a change in which projects receive priority funding. New government leaders might abandon an ongoing project and transfer funds to another project, causing project termination at the implementation stage. In addition, project site clearance usually faces many conflicts, such as internal and interface conflicts, between project teams and communities [17]. One of the most important causes is difference in policies and regulations of different areas, such as lacking uniform standards between the price of land requisition compensation and resettlement regulations. The constant adjustment of land policy often impacts PFM, LFC, and DP as well.

Countermeasures: It is recommended that foreign firms could overcome CP risks by paying more attention to the analysis and prediction of relevant laws and regulations systems, as well as providing anti-graft training for their staff who are stationed in Vietnam. Employing local partners to obtain approvals and permits is also recommended. In addition, foreign firms are suggested to take some appropriate measures such as government guarantees and purchase political risk insurance to make reactions timely when the policy changes. In addition, issues due to $\mathrm{CP}$ can be mitigated by execution of law in terms and conditions through terms in the contract. Clarifying payment matters, time of land requisition, and refund procedures should be cleared in the contract. Furthermore, attempting FIDIC mode or utilizing claim for compensation in order to reduce risks due to imperfect policies is also recommended.

\subsection{Impact of $L F C$}

Regarding the influence of LFC on SD, its comprehensive influence ranks third (0.372) while its direct impact ranks second (0.268). LFC, apart from directly impacting SD, can indirectly influence SD through directly impacting DP. Simultaneously, LFC is directly impacted by CP and CEE. LFC consists of poor financial ability of the contractor, owner's excessive change orders, and financial difficulties of the owner. LFC not only leads to SD in Vietnam, but in many other nations as well, especially in developing nations, e.g., Nigeria, Ghana, Malaysia, Thailand [2,3,13,20]. Abdul-Rahman et al. addressed that lacking funds may affect the project's cash flow and lead to delay in site acquisition, which consequently causes SD of the project [1]. In the construction process, the contractors need to pay a large amount in advance for various reasons, and if the financial ability of the contractor is poor or the financial ability of the owner is difficult, capital for the project might face finance problems resulting in SD.

Countermeasures: The lack of funds will deeply influence IHP operations, and to avoid risks due to this issue, the owners are recommended to prepare an available fund and build a reasonable financial plan for the project. In the process of bidding, the owners should strictly review the contractor's fiscal capacity. On the other hand, the contractors should consider the risks of their own, including funds and loans. In addition, the contractors are suggested to cooperate with banks, which can provide credit guarantees for the contractors to manage risks. Furthermore, the contractors are also recommended to cooperate with other companies to integrate resources; thus, a win-win situation can be achieved.

\subsection{Impact of PFM}

Concerning influence of PFM on SD, its comprehensive influence ranks fourth (0.372) while its direct effect ranks third (0.235). PFM, apart from directly influencing SD, can indirectly impact SD by directly influencing DP. It is similar to LFC. PFM is directly impacted by CP and CEE. PFM includes unreasonable use of fund allocation by the owner, poor contractor forecasting of cash flow, and low bid price by the contractor. Prümer indicated that the most important aspect of cash flow management is to avoid extended cash shortages that are caused by big gaps between cash inflows and outflows [18]. In Vietnam, due to the high demand of infrastructure projects, this is a common phenomenon in the construction process wherein a large number of project-specific funds are often misappropriated, diverted, and counteracted, leading to cash shortages for a long time that cannot be paid on time for the construction unit during construction progress billings. In addition, in the process of construction, in the case of the contractors' poor forecasting of cash flow, the contractors may face a working fund shortage leading to expenses for raw materials. Machinery cannot be paid on time so raw materials may not be delivered to the site resulting in SD as well.

Countermeasures: The owners are recommended to have clear and fixed-dedicated funding projects instead of launching too many projects at the same time. During the process of tender, the owner should set the bottom price under the premise for ensuring project's duration and quality, and ignore the bids that are at a very low price. On the other hand, the contractors are 
suggested to adopt a quota system to avoid handling too many projects at the same time. The contractors and the owners should be educated on the importance of cash flow management and financial and business management to ensure a good cash flow management in the construction progress.

\subsection{Impact of $D P$}

Regarding impact of DP on SD, its direct influence is highest (0.309) but the comprehensive impact is smallest (0.31). DP is influenced by LFC, PFM, CEE, and CP. DP includes delayed payment of the owner for finished work to the contractors, complication in applying for reimbursement of finished work, tardy of acceptance inspection for finished work, and delayed payment by the contractor for finished work done by the sub-contractors. In Vietnam, slow payment of finished work is a very common issue by the contractors. This often exists in government-funded projects where payment procedure always takes a long time [15]. Delay in paying the contractors will subsequently jeopardize the contractor's cash flow, resulting in financial difficulties by the sub-contractors. In addition, lack or inadequacy of capable consultants for handling large projects leads to poor site management, slowing down the acceptance of finished work, resulting in a delay construction period [17]. A delayed payment by a party who is involved in the process of payment may influence the supply chain of payment in the whole project.

Countermeasures: All parties should identify clear responsibilities of each party in the contract. The owners are suggested to build a reasonable financial plan to pay the contractor according to the contract agreement. In addition, the owners are suggested to adopt financial assignment in order to deal with suppliers supplying materials for the contractor and receive payment directly from the owners. On the other hand, the contractors are recommended to allocate and arrange the construction schedule properly according to the owner's fiscal capacity. In addition, during the process of project, the contractors are recommended to communicate and coordinate with the project's manager and supervision department frequently in order to properly deal with the many kinds of engineering contradictions. The contractors also are suggested to get ready for construction settlement during examination and approval of the project. The contractors should also pursue for unpaid project funds by the owner. The contractors could also use or refer to the FIDIC contract conditions for construction.

\section{Conclusions}

The current study identifies the financial-related risk factors causing SD of IHPs in Vietnam, and discusses their effects on SD and interaction relations among them using the SEM method and a questionnaire survey technique.

Obtained results show that rankings of comprehensive effects of financial-related factors on SD of the IHPs in Vietnam from highest to lowest respectively: CEE, CP, LFC, DF and PFM. Consistent with the literature, the financial external risks, i.e., $\mathrm{CEE}$ and $\mathrm{CP}$ play prominent roles in the IHPs and they indeed are issues in Vietnam.

The study also reveals the influence path of financial-related factors on SD and interaction relations among them. So, the risk manager should not only consider its direct effect, but should also address its indirect effect because the interaction influences among them can definitely change their comprehensive impact on SD. When the influence of any factor varies, the risk manager also should reanalyze their acting mechanism and influencing extent in whole to conduct effective measures. The corresponding measures dealing with these risks are discussed in detail.

This study provides an essential tool for participants of IHPs in Vietnam to assess the potential impacts of financialrelated factors on SD. It also provides a set of implications that can help participants of IHPs adopt proper preventive actions to effectively manage the SD risk in the implementation of IHPs. The results, therefore, are referable for other similar developing countries.

\section{Acknowledgments}

We would like to express sincere appreciation to experts at Le Quy Don Technical University, Hanoi, Vietnam for their valuable comments to improve this manuscript. The authors also acknowledge the respondents for their enthusiasm. This work is financially supported by Chengdu Accounting Association (KT2016-Z1), and Web Culture Project Sponsored by the Humanities and Social Science Research Base of the Sichuan Provincial Education Department (WLWH17-31).

\section{References}

1. H. Abdul-Rahman, C. Wang, R. Takim, and S. Wong, (2011), "Project schedule influenced by financial issues: Evidence in construction industry", Scientific Research \& Essays, Vol. 6, No. 1, pp. 205-212. 
2. A. A. Aibinu, and G. O. Jagboro, (2002), "The effects of construction delays on project delivery in Nigerian construction industry", International Journal of Project Management, Vol. 20, No. 8, pp. 593-599.

3. W. E. Alaghbari, M. R. A. Kadir, A. Salim, and Ernawati, (2007), "The significant factors causing delay of building construction projects in Malaysia", Engineering Construction \& Architectural Management, Vol. 14, No. 2, pp. 192-206.

4. A. Aleshin, (2001), "Risk management of international projects in Russia", International Journal of Project Management, Vol. 19, No. 4, pp. 207-222.

5. J. C. Anderson, and D. W. Gerbing, (1988), "Structural equation modeling in practice: A review and recommended two-step approach", Psychological bulletin, Vol. 103, No. 3, pp. 411.

6. S. A. Assaf, and S. Al-Hejji, (2006), "Causes of delay in large construction projects", International Journal of Project Management, Vol. 24, No. 4, pp. 349-357.

7. K. A. Bollen, (1989), "A New Incremental Fit Index for General Structural Equation Models", Sociological Methods \& Research, Vol. 17, No. 3, pp. 303-316.

8. K. A. Bollen, (1987), "Total, Direct, and Indirect Effects in Structural Equation Models", Sociological Methodology, Vol. 17, No., pp. 37-69.

9. S. M. El-Sayegh, (2008), "Risk assessment and allocation in the UAE construction industry", International Journal of Project Management, Vol. 26, No. 4, pp. 431-438.

10. S. M. El-Sayegh, and M. H. Mansour, (2015), "Risk Assessment and Allocation in Highway Construction Projects in the UAE", Journal of Management in Engineering, Vol. 31, No. 6, pp. 1-12.

11. M. Fernandez-Dengo, N. Naderpajouh, and M. Hastak, (2012), "Risk Assessment for the Housing Market in Mexico", Journal of Management in Engineering, Vol. 29, No. 2, pp. 122-132.

12. C. Fornell, and D. F. Larcker, (1981), "Evaluating structural equation models with unobservable variables and measurement error", Journal of Marketing Research, Vol. 18, No. 1, pp. 39-50.

13. Y. Frimpong, and J. Oluwoye, (2003), "Significant Factors Causing Delay and Cost Overruns in Construction of Groundwater Projects in Ghana", Journal of Construction Research, Vol. 04, No. 2, pp. 175-187.

14. Y. Hong, D. W. Chan, A. P. Chan, and J. F. Yeung, (2011), "Critical analysis of partnering research trend in construction journals", Journal of management in engineering, Vol. 28, No. 2, pp. 82-95.

15. L. Le-Hoai, Y. Dai Lee, and J. Y. Lee, (2008), "Delay and cost overruns in Vietnam large construction projects: A comparison with other selected countries", KSCE journal of civil engineering, Vol. 12, No. 6, pp. 367-377.

16. F. Y. Y. Ling, and V. T. P. Hoang, (2010), "Political, Economic, and Legal Risks Faced in International Projects: Case Study of Vietnam", Journal of Professional Issues in Engineering Education \& Practice, Vol. 136, No. 3, pp. 156-164.

17. N. D. Long, S. Ogunlana, T. Quang, and K. C. Lam, (2004), "Large construction projects in developing countries: a case study from Vietnam", International Journal of project management, Vol. 22, No. 7, pp. 553-561.

18. M. Prümer, (2005), "Cash Flow Management", Springer-Verlag.

19. O. Taylan, A. O. Bafail, R. M. S. Abdulaal, and M. R. Kabli, (2014), "Construction projects selection and risk assessment by fuzzy AHP and fuzzy TOPSIS methodologies", Applied Soft Computing, Vol. 17, No. 4, pp. 105-116.

20. S. U. R. Toor, and S. O. Ogunlana, (2008), "Problems causing delays in major construction projects in Thailand", Construction Management \& Economics, Vol. 26, No. 4, pp. 395-408.

21. M. T. Wang, and H. Y. Chou, (2003), "Risk Allocation and Risk Handling of Highway Projects in Taiwan", Journal of Management in Engineering, Vol. 19, No. 2, pp. 60-68.

22. S. Q. Wang, M. F. Dulaimi, and M. Y. Aguria, (2004), "Risk management framework for construction projects in developing countries", Construction Management \& Economics, Vol. 22, No. 3, pp. 237-252.

23. Z. Wenxi, and C. Danyang, "Expressway management risk evaluation based on fuzzy neural networks," Proceedings of the Intelligent Computation Technology and Automation, 2009. Second International Conference on ICICTA'2009, IEEE.

24. T. Zayed, M. Amer, and J. Pan, (2008), "Assessing risk and uncertainty inherent in Chinese highway projects using AHP", International Journal of Project Management, Vol. 26, No. 4, pp. 408-419.

25. S. D. Zoysa, and A. D. Russell, (2003), "Knowledge-based risk identification in infrastructure projects", Canadian Journal of Civil Engineering, Vol. 30, No. 3, pp. 511-522. 